way consumer resistance to child resistant containers would be lessened. The general public is becoming accustomed to such containers and would probably accept their selective use for household products. From the present study it would appear that bleach, paraffin, and turpentine would be the most appropriate products for such packaging.

Plant poisonings are uncommon, and the falling number of children admitted with laburnum seed poisoning reflects an increasing awareness of the relative non-toxicity of these seeds ${ }^{5}$ and the fact that most children so poisoned are no longer admitted to hospital. Mild to moderate symptoms occur in a small proportion but generally do not warrant admission to hospital.

The figures for poisoning in children aged over 10 show two clearcut and important trends. The first is the steady increase in self poisoning among young adolescent girls, and the second the increase in admissions of teenage boys after ingestion of alcohol. Alcohol consumption is a growing and major problem among older children. A fairly recent death from poisoning in Newcastle was of a 12 year old boy who drank two bottles of sherry and inhaled vomit on his way to hospital. We presume that abuse of alcohol is part of the adolescent search for "kicks" and is similar to glue sniffing, which in this area has, until recently, been a cause of relatively few hospital admissions.

The main thrust of the prevention of poisoning in young children must be the extension of the use of child resistant containers. The history of the introduction of child resistant containers in the United States for both medicinal and nonmedicinal products by the Poison Prevention Packaging Acts was recently reviewed. ${ }^{6}$ From this there is clear evidence that such containers are effective, and in the United Kingdom this has already been shown for salicylates. ${ }^{3}$ Unfortunately, regulations rather than voluntary agreements appear to be necessary before most safety measures are effective, but the reduction in both suffering and occasional death must surely be worth a slight loss of freedom. There must of course be exceptions for the elderly and infirm, but the common occurrence of poisoning episodes in grandparents' homes should not be forgotten. Continued efforts to reverse the negative approach of some pharmacists must continue, and parental responsibility for the safety of their children should be emphasised and should include advice to parents to demand medicines in child resistant containers. Direct education of 5 to 9 year old children might also be beneficial.

The disturbing trends among older children towards both self destructive episodes and alcohol poisoning give cause for considerable concern. It represents one manifestation of the psychosocial problems that children are now experiencing. The increasing use and availability of alcohol by society as a whole must at least be partly responsible for this disturbing trend in adolescents.

\section{References}

${ }^{1}$ McLean W. Child poisoning in England and Wales: some statistics on admissions to hospital, 1964-1976. Health Trends 1980;12:9-12.

${ }^{2}$ Department of Health and Social Security. Hospital in-patient enquiry for 1977. London: HMSO, 1981.

${ }^{3}$ Sibert JR, Craft AW, Jackson RH. Child resistant packaging and accidental child poisoning. Lancet $1977 ; \mathrm{ii}: 289-90$.

${ }^{4}$ Goulding $\mathrm{R}$, Ashforth EK, Jenkins $\mathrm{H}$. Household products and poisoning. Br Med F 1978;i:286-7.

${ }^{5}$ Bramley A, Goulding R. Laburnum "poisoning." $\mathrm{Br}$ Med $\mathcal{F} 1981 ; 283$ : 1220-1.

6 Walton WW. An evaluation of the Poison Prevention Packaging Act. Pediatrics 1982;69:363-70.

(Accepted 7 April 1983)

\title{
Alcohol and the fetus in the west of Scotland
}

\author{
JOHN O BEATTIE， RUTH E DAY，FORRESTER COCKBURN， RAM A GARG
}

\section{Abstract}

Forty children with the fetal alcohol syndrome were identified in the west of Scotland. All were growth retarded and had abnormal facial features, and all those who were tested were found to have nuerological or developmental abnormalities. Two children died of associated physical defects. Most of the mothers were socially deprived, and all had drunk heavily while pregnant. Three women had subsequently died.

These findings provide clear evidence that in the west of Scotland maternal alcohol abuse during pregnancy is a significant cause of morbidity and mortality in children.

University Department of Child Health, Royal Hospital for Sick Children, Yorkhill, Glasgow G3 8SJ

JOHN O BEATTIE, MB, MRCP, registrar

RUTH E DAY, MB, MRCP, consultant paediatrician

FORRESTER COCKBURN, MD, FRCP, professor of child health

Department of Paediatrics, Southern General Hospital, Glasgow RAM A GARG, $M B$, paediatric registrar

Correspondence to: Professor Forrester Cockburn.

\section{Introduction}

In the past 10 years there has been increasing concern about the detrimental effects on the fetus of maternal alcohol abuse during pregnancy. During this period over 800 clinical and research papers relating to the teratogenic effects of alcohol have been published. ${ }^{1}$ The features shown by children affected by this fetal alcohol syndrome include growth failure before and after birth; central nervous system disorder (hypotonia, irritability and jitteriness, retardation, poor coordination, hyperkinesis); craniofacial abnormalities (microcephaly, short palpebral fissures, ptosis, strabismus, epicanthic folds, midfacial hypoplasia, hypoplastic philtrum, thin upper lip, and short upturned nose); and various associated physical abnormalities (of eyes, ears, mouth, cardiovascular system, genitourinary system, skeleton; haemangiomas; and hernias). ${ }^{2}$ Criteria for clinical diagnosis of the condition have been proposed. ${ }^{3}$

Although many questions about the pathogenesis remain unanswered, anxiety about the danger of even moderate drinking during pregnancy is now so great that in the United States the Surgeon General has advised mothers to abstain totally from drinking alcohol during pregnancy, ${ }^{4}$ a view recently echoed by the Royal College of Psychiatrists in Britain. ${ }^{5}$ Except for one recent study ${ }^{2}$ there has been little reported clinical experience of the fetal alcohol syndrome from Britain, and it has been suggested that the problem is insignificant in this country. ${ }^{\circ}$ This is surprising since alcohol abuse is certainly as common 
in the United Kingdom as in many countries with experience of the condition.

We therefore set out to determine whether the fetal alcohol syndrome was an important problem in the west of Scotland, an area of established high alcohol abuse.

\section{Patients and methods}

Because of the developmental and physical abnormalities which children with the fetal alcohol syndrome show we assumed that grossly affected children would be unlikely to escape contact with the paediatric services within the region. We therefore sought cases by asking 15 consultant paediatricians at the Royal Hospital for Sick Children, Glasgow, and in surrounding paediatric units who were well aware of the clinical features of the syndrome to identify affected children known to them. The case records of children with the fetal alcohol syndrome who were or had been under their care were examined and the details extracted.

Medical, psychiatric, and demographic data on the mothers of affected children were obtained from the children's case records. In addition the general practitioners of 37 of the 39 families eventually studied were interviewed by telephone. They were aware that the infants had suspected congenital anomalies and that we were looking for likely teratogens. The practitioners were asked about the mothers' alcohol consumption, smoking habits, and drug ingestion during pregnancy. Mothers were not questioned directly about their alcohol intake, although some had freely volunteered information about their drinking.

Twenty seven of the affected children were examined by at least one of the authors. In 12 cases we used photographs to assess the presence of facial dysmorphism, and in one child who had died from congenital heart defects the clinical and pathological reports confirmed the presence of the fetal alcohol syndrome.

Height and weight centiles of the children were determined using the standards for children established by Tanner et $a l^{7}$ and by Gairdner and Pearson. ${ }^{8}$

\section{Results and comment}

\section{THE CHILDREN}

Forty children born in the west of Scotland from 1971 to 1981 were identified as having clinical findings that met the criteria for a diagnosis of the fetal alcohol syndrome. This group comprised 21 boys and 19 women and included one sibling pair.

The calendar year of diagnosis of the fetal alcohol syndrome was determined for each child: six had been identified in 1976-7, 12 in 1978-9, and 22 in 1980-1. It is unclear whether this reflects a true increase in the incidence of the syndrome or simply a heightened clinical awareness of this condition.

All 40 children had facial features consistent with the condition. These included prominent epicanthic folds, a broad flat nasal bridge with retrousée nose, an indistinct or absent philtrum and a thin upper lip (fig 1).

TABLE 1-Growth characteristics in 40 children with the fetal alcohol syndrome at a mean age of $2 \cdot 2$ years. Results are number of children

\begin{tabular}{lcccccc}
\hline \multicolumn{1}{c}{ Centile: } & 3 & 10 & 25 & 50 & 75 & 90 \\
\hline Weight & 24 & 15 & 1 & 0 & 0 & 0 \\
Length & 22 & 16 & 1 & 1 & 0 & 0 \\
Occipitofrontal circumference & 24 & 11 & 3 & 0 & 1 & 1 \\
\hline
\end{tabular}

TABLE II-Social class distribution of $\mathbf{4 0}$ children with the fetal alcohol syndrome compared with that of the newborn population in Scotland. Results are percentages (numbers in parentheses)

\begin{tabular}{|c|c|c|c|c|c|}
\hline Class: & I & II & III & IV & $\mathbf{V}$ \\
\hline $\begin{array}{l}\text { Children with fetal alcohol } \\
\text { syndrome } \\
\text { Scottish newborn infants* }\end{array}$ & $\begin{array}{l}5 \cdot 0(2) \\
7 \cdot 1\end{array}$ & $\begin{array}{c}2.5(1) \\
16.7\end{array}$ & $\begin{array}{l}17 \cdot 5(7) \\
49 \cdot 4\end{array}$ & $\begin{array}{l}15 \cdot 0(6) \\
17 \cdot 2\end{array}$ & $\begin{array}{c}60 \cdot 0(24) \\
7 \cdot 7\end{array}$ \\
\hline
\end{tabular}

-Data derived from the annual report of the Registrar General 1981.
The birth weight could be determined for all 40 children. Many mothers were unsure of the duration of pregnancy, and the gestational ages used came from obstetric and paediatric clinical assessments. Figure 2 shows the distribution of birth weight by gestation and the subsequent growth pattern of 34 children. There was a strong bias towards low birth weight, with no child reaching the 50th centile of weight for gestational age. In 23 infants birth weights were below the 10 th centile. This growth pattern was also seen with head cir-

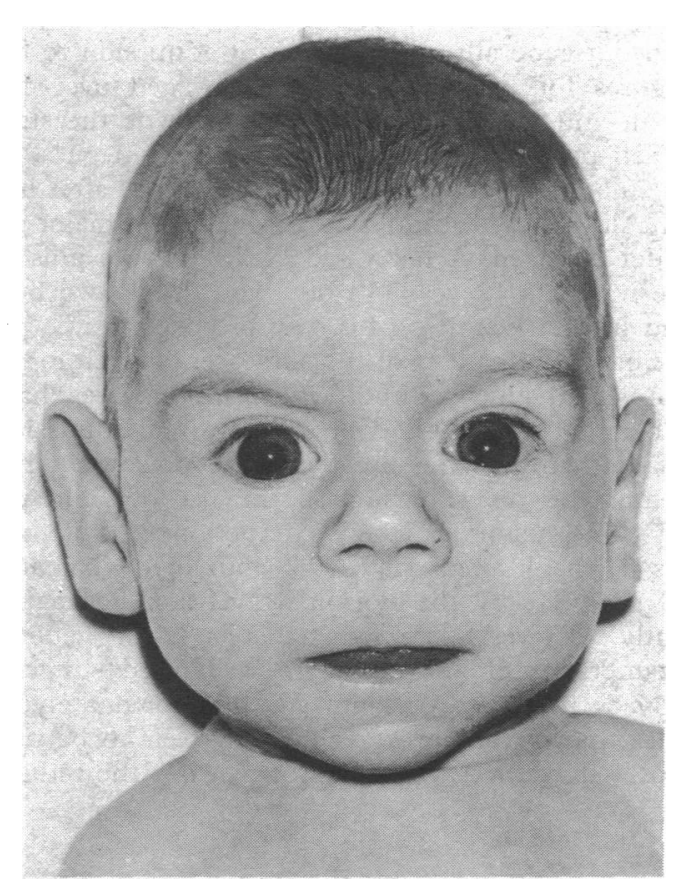

FIG 1-Infant with facial features of fetal alcohol syndrome. Note short upturned nose, absent philtrum, and thin upper lip.

cumference at birth and head growth. Table I shows the subsequent growth of these children at a mean age of $2 \cdot 2$ years (range 6 weeks to 10 years). Thirty nine children were below the 10th centile for weight, 38 below the 10th centile for height, and 35 below the 10th centile for cranial circumference. Twenty four children had a head circumference below the 3 rd centile. The child with a head circumference approaching the 90th centile reflected the unusual but established occurrence of hydrocephalus in children with the fetal alcohol syndrome.

\section{Associated physical defects}

Twenty children had a cardiac abnormality. In 10 this consisted of persistent but probably organically unimportant systolic murmurs. Four children had isolated ventricular septal defects, two pulmonary stenosis, and one an atrial septal defect. Three children had complex congenital heart disease and both deaths were in this group. One of the infants who died had combined atrial and ventricular septal defects and a patent ductus arteriosus and was in cardiac failure despite medical treatment. Corrective cardiac surgery was attempted, but he did not survive. The second infant had a large ventricular septal defect and a persistent left superior vena cava. His cardiac failure was controlled by medical treatment, but he developed bowel obstruction associated with a large inguinal hernia and died after surgery.

Three children had abnormalities of the renal tract. In two asymptomatic children, one with unilateral duplication of the upper renal tract and the other with unilateral hydronephrosis, the diagnosis was made after cardiac catheterisation and angiocardiography. The other child had recurrent urinary tract infection with unilateral pelvicaliceal dilatation. Minor abnormalities of the external genitalia were found in two girls, in whom the genital labia were hypoplastic. Two boys 
had minor penile abnormalities-hypospadias in one and phimosis in the other. Three boys had unilateral undescended testes and five had inguinal hernias.

Nine children had major abnormalities of their palmar creases, most having bilateral single transverse creases. Detailed dermatoglyphic analysis was not performed. function-one hypotonia, one seizures, and the third gross hyperactivity. As others have observed, the degree of developmental delay seemed to correlate with the severity of physical dysmorphism. ${ }^{\circ}$ Neurological deficit in one form or other was present in 17 children: nine had seizures, four fine motor dysfunction, two ataxia, two hypotonia, two spasticity, two optic nerve hypoplasia, one nystagmus, one hydrocephalus, and one hyperactivity.

\section{THE MOTHERS}

The 39 mothers of the children were also studied. One gave birth to two affected infants, and only maternal details relating to cause of the social circumstances of the children and the retrospective nature of the study, we could not trace them all to perform stan-

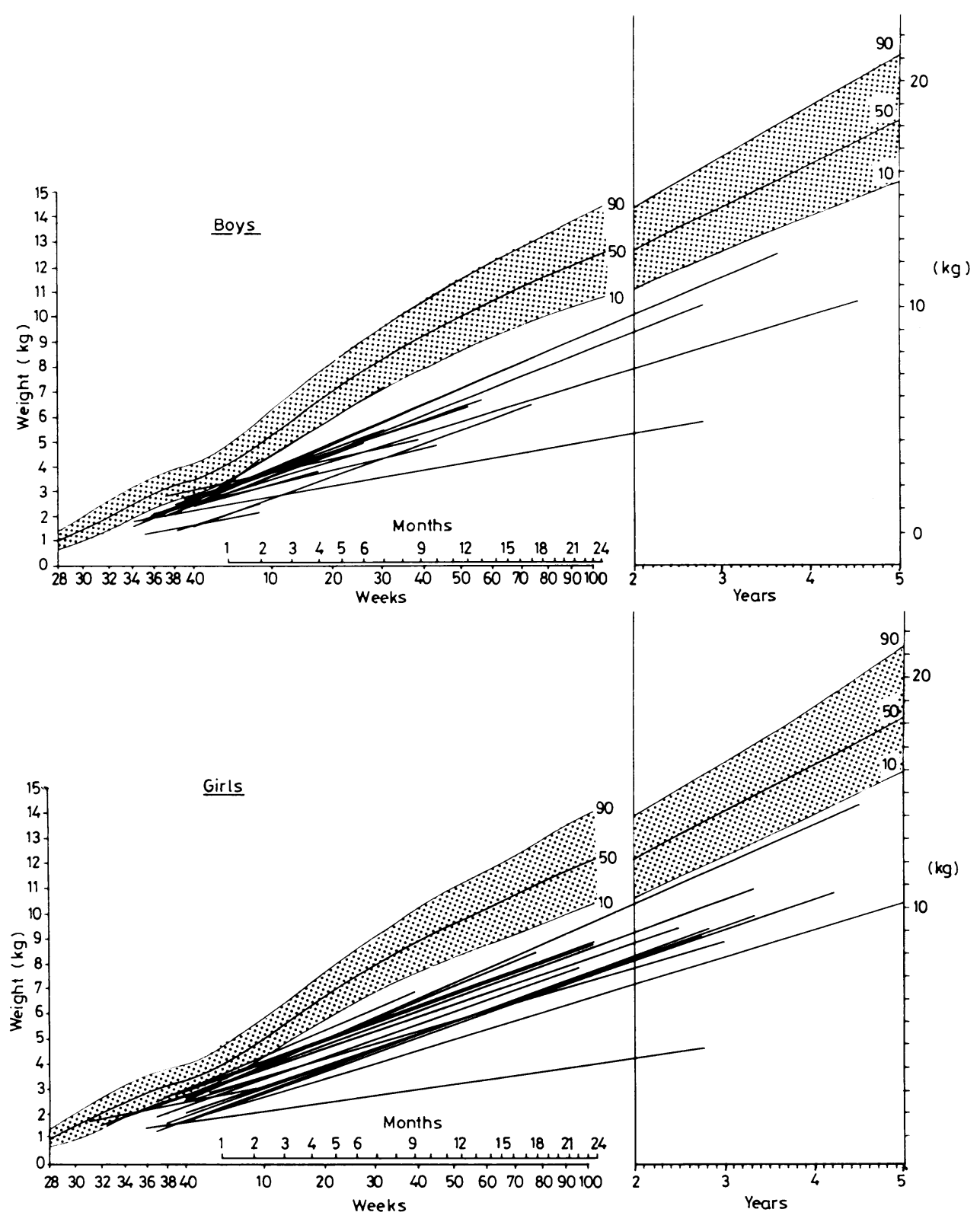

FIG 2-Pattern of weight gain in 17 boys and 17 girls with fetal alcohol syndrome. Catch up growth was not seen.

dardised cognitive testing. In many of the older children the results of Griffiths or Stanford Binet testing were available, though in the younger children non-standardised assessment had often been performed. Because of the variety of assessment methods used we simply expressed the degree of psychomotor retardation as mild, moderate, or severe. It should be recognised that early testing may well underestimate or fail to show later cognitive difficulties and our figures may well underestimate the extent of these children's difficulties. Of the 31 children tested seven were severely retarded, two were moderately retarded, and 19 showed mild developmental delay. Three children appeared normal, but each had some neurological dys- the index case have been included. The mothers' ages at the time of delivery of their affected infants, which could be determined in 38 cases, ranged from 19 to 41 years, with a mean of 29.5 years. Eighteen were married at the time of conception of an affected child. Of the remainder, 12 women had never married, six were separated from their husbands, and three were divorced. The mean number of pregnancies before the conception of the affected child was three (range 0-8). Before the conception of the affected child 18 mothers $(46 \%)$ had had at least one unsuccessful pregnancy (most of them spontaneous abortions), with a total of 31 unsuccessful pregnancies.

All mothers were known to be heavy drinkers, but details of the 
drinking patterns, types of alcohol ingested, and variation with stage of pregnancy were available in detail for only a few. Although all types of alcohol were consumed, strong beers and vodka were favourites. The minimum intake reported during pregnancy was six measures of vodka a day and the maximum one bottle of vodka daily. No mother was known to abuse drugs, although one mother, the youngest, admitted to solvent abuse as an adolescent. Two mothers spent short periods of their pregnancies in prison because of alcohol related crimes.

Nineteen mothers were known to smoke at least 20 cigarettes daily, but this was probably an underestimate of the habit. Two mothers had had a course of oral metronidazole during pregnancy because of trichomonal infection, both administered while the mothers were inpatients in hospital wards. One mother was on regular phenytoin and phenobarbitone treatment for control of seizures.

Fifteen mothers had been seen by a psychiatrist some time before conception of the affected child. Such referrals were generally made for alcohol abuse alone, or alcoholism complicated by incidents of parasuicide with non-accidental drug overdose. Three women were also frankly depressive. In 32 cases the general practitioners were aware of maternal alcohol abuse- 27 mothers were considered by their general practitioners to be frankly alcoholic, while five were simply considered to have an "alcohol problem." In several cases it was only when the affected child was diagnosed that the maternal alcohol problem became evident.

Seven mothers also had physical illness associated with alcohol abuse: four had alcohol induced hepatic cirrhosis; one had peripheral neuropathy; one had an unexplained macrocytosis; and, at the time of the study, another was an inpatient in a general hospital with an "alcohol induced coma." A significant maternal mortality was found: three mothers had died since giving birth to the affected child. Two of them, both depressed alcoholics, committed suicide-one by salicylate overdose, the other by drowning in the River Clyde. The remaining maternal death was due to alcohol related hepatic failure. Details of alcohol abuse in the husband or consort were difficult to obtain, but alcohol abuse was not uncommon. In one case an affected child's father had later died in hepatic coma from longstanding alcoholic cirrhosis.

\section{SOCIAL CLASS DISTRIBUTION}

We tried to determine the socioeconomic status of the families from which these children came by allocating them to social classes on the basis of their fathers' occupations according to the Registrar General's Classification of Occupations. Since fewer than half the mothers were married at the time of conception allocation by maternal occupation or that of the natural father (if known) was substituted. In some cases this was impossible and classification was based on the occupation of the child's maternal grandfather.

Table II shows the social class distribution of affected children compared with the normal class distribution of newborn infants in Scotland. Even allowing for a lower socioeconomic population in the west of Scotland, bias towards the lowest socioeconomic group was clearly evident.

\section{Discussion}

Although concern about the effects of maternal alcohol abuse in pregnancy dates back to biblical times, only recently have the teratogenic effects of alcohol been explored in detail. Initial scepticism among doctors has now been replaced by a general acceptance that an identifiable syndrome can be produced in the fetus by women drinking heavily in pregnancy. Diagnostic criteria have been suggested by the Fetal Alcohol Study Group of the Research Society on Alcoholism, ${ }^{3}$ and centres have started intervention programmes for detecting and counselling pregnant women who are drinking heavily.10 In the USA the state of New York estimates a yearly cost of $\$ 155 \mathrm{~m}$ directly related to the birth of alcohol damaged children. ${ }^{11}$

In this study we have identified 40 children who have significant problems due to maternal alcohol abuse, 22 of them identified in the two years 1980-1. This indicates that in the west of Scotland the fetal alcohol syndrome is a problem and one which may be increasing. The apparent occurrence of only sporadic cases of the syndrome in some areas of the UK perhaps reflects the variation in drinking habits of local populations. Several studies have emphasised the relative frequency of alcohol abuse in the west of Scotland, where 1 in 10 men and more than 1 in 100 women may be "problem drinkers," half of them being classed as "alcoholics." ${ }_{12}$ Kilich and Plant, using an alcohol problem score based on the incidence of alcohol related mortality, morbidity, and crime in each part of the country, have clearly shown a progressive prevalence of these problems as one moves north in the UK. ${ }^{13}$ An alternative explanation for the apparent low incidence of the fetal alcohol syndrome elsewhere in the UK is that the syndrome is still not recognised, the children being diagnosed as having short stature or intellectual retardation of unknown cause, or isolated congenital heart disease, cleft palate, or hernias.

The various social and medical measurements of alcohol abuse suggest that alcohol problems among women are increasing, ${ }^{14}$ perhaps especially in those of childbearing age. ${ }^{15}$ The fetal alcohol syndrome is likely therefore to become more common. Recognition of the disorder is important because advice to the mother may prevent the birth of a second affected child. In this study we included only children with undisputed fetal alcohol syndrome whose mothers were heavy drinkers. Nevertheless, it is increasingly recognised that moderate maternal drinking may affect the fetus, and this is perhaps the area of greatest concern. One recent study has shown that as few as 10 drinks a week during early pregnancy may be associated with significantly reduced birth weight. ${ }^{16}$ Further prospective research is urgently needed to define the origins and extent of the problem of the fetal alcohol syndrome in the UK so that appropriate resources can be allocated for education, intervention, and prevention. Until more is known, a policy of total abstinence, from alcohol from before conception if possible and certainly during pregnancy, appears to be the only sensible way to ensure an unaffected child with full intellectual potential.

We thank the general practitioners and consultant paediatric physicians and surgeons of the west of Scotland for providing details of patients under their care. Special thanks are expressed to $\mathrm{Dr}$ M M Kerr, Dr I Ferguson, and Dr J McLure for advice and support with this study; Miss Jean Hyslop for graphics; and Miss Gill Sinclair for typing the manuscript.

\section{References}

${ }^{1}$ Abel EL. Fetal alcohol syndrome: a bibliography. Boca Raton, Florida: CRS Press, 1981.

${ }^{2}$ Halliday HL, Reid MMcC, McClure G. Result of heavy drinking in pregnancy. Br $\mathcal{F}$ Obstet Gynaecol 1982;89:892-5.

Rosett HL. A clinical perspective on the fetal alcohol syndrome. Alcoholism (NY) 1980;4:119-22.

- Surgeon General's Advisory Committee on alcohol and pregnancy. Report. FDA Drug Bulletin 1981;11(2):9-10.

${ }^{5}$ Anonymous. New advice about alcohol and pregnancy. Lancet $1982 ; \mathrm{i}: 636$.

${ }^{6}$ Kessell N. The fetal alcohol syndrome from the public health standpoint. Health Trends 1977;9:86-9.

7 Tanner JM, Whitehouse RH, Takaishi M. Standards from birth to maturity for height, weight, height velocity and weight velocity. British children 1965. Arch Dis Child 1966;41:454-71.

${ }^{8}$ Gairdner D, Pearson J. A growth chart for premature and other infants. Arch Dis Child 1971;46:783-7.

${ }^{9}$ Streissguth AP, Herman CS, Smith DW. Intelligence, behaviour and dysmorphogenesis in the fetal alcohol syndrome: a report on 20 patients. F Pediatr 1978;92:363-7.

1" Rosett HL, Oullette EM, Weiner L, Owens E. Therapy of heavy drinking during pregnancy. Obstet Gynecol 1978;51:41-6.

11 Russell $M$. The impact of alcohol-related birth defects (ARBD) on New York State. Neurobehav Toxicol 1980;2:277-83.

12 Saunder WM, Kershaw PW. The prevalence of problem drinking and alcoholism in the West of Scotland. Br $\mathcal{F}$ Psychiatry 1978;133:493-9.

${ }^{13}$ Kilich SA, Plant MA. Regional variations in the level of alcohol-related problems in Britain. $\mathrm{Br} \mathcal{F}$ Addict $1981 ; 76: 47-62$.

14 Shaw $S$. The causes of increasing drinking problems among women. In: Camberwell Council on Alcoholism, ed. Women and alcohol. London: Tavistock Publications, 1980.

15 Central Statistical Office. Social Trends. No 11. London: HMSO, 1981.

${ }^{16}$ Wright JT, Waterson EJ, Barrison IG, et al. Alcohol consumption, pregnancy and low birth weight. Lancet (in press). 